\title{
Appraising emergency contraceptives knowledge and use among female youth corp members in Nigeria
}

\begin{abstract}
Background: Emergency Contraception (EC) will help forestall unintended pregnancies, following an unprotected sexual intercourse or failure of regular family planning methods. EC knowledge is essential for every woman in the reproductive age group, especially single women who are unable to abstain from unprotected sex. Nevertheless, this knowledge and the utilization of this essential reproductive health product is poor among women across the globe. The female NYSC member of Nigeria stand a greater risk of unintended pregnancies, but little or no attention has been paid to this.
\end{abstract}

Objectives: The present study is informed by the necessity to asses among female NYSC members' knowledge and utilization of EC and come out with information that may help the public and policy makers in fighting unintended pregnancies and its consequences in Nigeria.

Methods: 181 self-structured, validated questionnaires were distributed among consenting female NYSC members systematically drawn from the 23 Local Government Areas of Sokoto State. SPSS version 20.0 statistical package was used to manage the database.

Results: $22.8 \%$ of the respondents were found to have good knowledge of EC. Only $44.4 \%$ of this group believed it is morally alright to use EC. $39.5 \%$ of the respondents that confirmed being involved in an act that required EC ever used it. We also found that tribe/ ethnicity and geopolitical zones of respondents influenced their EC knowledge $\left(\chi^{2}=8.505\right.$, $\mathrm{p}=0.037$ and $\chi^{2}=17.839, \mathrm{p}=0.003$, respectively).

Conclusion: To address unintended pregnancies and the consequences among our young female graduates who stand a huge risk in this respect, formal sex education, advance provision of EC services and handy information strategies such as handbills on EC need be encouraged.

Keywords: emergency contraception, maternal deaths, fertility, female corps
Volume 10 Issue 5 - 2019

\author{
Adamu Jibril Bamaiyi; Tooyib Akintayo Azeez, \\ Kabiru Abdullahi Ladan \\ Department of physiology, Faculty of basic medical sciences, \\ College of health sciences, Usmanu danfodiyo university, Nigeria \\ Correspondence: Adamu Jibril Bamaiyi, Department of \\ physiology, Faculty of basic medical sciences, College of health \\ sciences, Usmanu danfodiyo university, Sokoto, Nigeria, Tel \\ +2348030925695 , \\ Email adamu.jibril@udusok.edu.ng, abamaiyi@yahoo.com
}

Received: August 28, 2019 | Published: September 17, 2019
Abbreviations: EC, emergency contraception; STDs, sexually transmitted diseases; NYSC, National youth service corp; Cu-IUD, copper-intrauterine device

\section{Introduction}

Emergency contraception (EC) works by utilizing hormones to inhibit or delay ovulation ${ }^{1-3}$ or by utilizing Copper-Intrauterine device/CU-IUD to prevent fertilization/implantation. ${ }^{2}$ In this regard, $\mathrm{EC}$ is the option left for a woman who got involved in an unprotected sex including forced sex, or failed in her regular birth control method and does not want to become pregnant. ${ }^{4,5} \mathrm{EC}$ will forestall unintended pregnancies, which in the United State constitute about half of all pregnancies, ${ }^{1,6}$ will help prevent about $50 \%$ of abortion cases also in the United State ${ }^{1}$ and will reduce maternal deaths that might accrue in the developing world like Nigeria, from induced abortions most of which are carried out by untrained hands. ${ }^{5,7-9}$ Nevertheless, EC awareness and practices worldwide, are still dismal even among women who are sexually active. ${ }^{1,6,10,11}$ Poor knowledge and concomitant low use of EC have been blamed both on disparate understanding about the mechanism of action of EC use, giving room for wrong timing and inefficiency, just as poor sex education has, consequently decreases its use. ${ }^{2,8}$ Further, the fear of rise in cases of sexually transmitted diseases (STDs) with the popularization of EC was allayed by an earlier study ${ }^{4}$ which showed that knowledge and use of condom was correspondingly high among students who use EC. And EC pills used in the correct doses have been reported not to negatively affect fertility as a side effect. ${ }^{1,3}$

Although the knowledge and use of EC among youths has been described in various settings of Nigeria and elsewhere, this requires being updated, as a way of evaluating how the fight is improving against unintended pregnancies and it sequeles. And to our knowledge, no study of such has been dedicated to female Nigerian National Youth Service Corp (NYSC) members. The female youth corps member in Nigeria deserves a special evaluation of her knowledge and use of EC, if unintended pregnancies, back-street abortions and the consequences are to be reduced. This group of youths are usually fresh graduates of Universities/Polytechnics who are usually affected by a number of factors, considered to be associated with increased sexual activities;

1) Higher social interactions; this is associated with high sexual activities. $^{5}$

2) Averagely in her 20s; a stage characterised by increased sexual flares. ${ }^{12}$ 
3) Observing a mandatory national assignment in an environment other than that she is indigenous to, thus parental influences are reduced which encourages more sexual behaviours. ${ }^{13}$

4) Higher possibilities to associate and make new friends whose sexual tendencies may be higher and likely to influence hers. ${ }^{14}$

5) On a grossly inadequate stipend of $\$ 650(<\$ 2)$ per day to cover all her expenses including feeding, accommodation, travels which may push her further into risk of sex for benefits. ${ }^{14}$

To this extent, we intend to evaluate the knowledge and utilization of EC in female youth corps members in Nigeria, which is a representative group of the various ethnic, religious and regions in the country. And we will also be examining how some socio-demographic factors could be associated with the knowledge and use of EC in this group.

\section{Methodology}

\section{Study background}

We carried out our study for about 12 weeks among female National Youth Service Corps (NYSC) members observing their obligatory national assignment in Sokoto State, Nigeria. Nigeria is stratified geographically into ethnicities, with each being grossly at variance to the other in terms of religious beliefs, educational levels and some other social orientations.

Briefly about the NYSC scheme: After the Nigerian civil war ended in 1970, the NYSC scheme was established by decree 24 in 1973 and later repealed and replaced by decree 51, 1993 with the aim of reconciling and rebuilding relations within the Nigerian state. As part of its objectives to build common ties among the Nigerian youths and promote national unity and integration, youths ( $\leq 30$ years) are assigned to a mandatory national assignment after their first or second degrees, for a period of 1 year, in a state other than their states of origin. By this, the NYSC members are exposed to ways of living of others Nigerians different from themselves. ${ }^{15}$ Therefore, the NYSC members in any state are essentially a collection of Nigerians of various religious groups, ethnicities and regions.

\section{Study design and population}

It was a cross-sectional descriptive study targeted at serving female NYSC members using a self-administered, validated, structured questionnaires (Appendix 1).

\section{Eligibility/inclusion criteria}

Serving Female youth corps members, within the age bracket of 18-29yrs and who consented to participate in the study were recruited. Indeed, all participants in the study are Nigerians.

\section{Exclusion criteria}

Non-NYSC, non-consenting and Non-Nigerians and males were excluded from the study.

Table I Case processing summary

\section{Sample size estimation}

Kish and Leslie formula was used to arrive at the 177 sample size, given that $13.3 \%$ of the sexually active female students in University of Port-Harcourt, Nigeria had ever used Emergency Contraception. ${ }^{16}$

\section{Sampling technique}

Stratified sampling method was employed

\section{Step I}

The respondents were categorised into zones. The Sokoto state NYSC scheme is divided into four (4) zones (Bodinga, Gwadabawa, Sokoto and Wurno zones) for ease of administration. And as at the time of our study, 949 female corps members were serving in the State (Appendix 2).

\section{Step 2}

A proportionate distribution of the respondents was made. The following were the distribution of the respondents, in accordance with each zone's contribution to the State 949 pool of female corps members;

$$
\begin{aligned}
& \text { Bodinga }: \frac{63 \times 180}{949} \approx 12 \\
& \text { Gwadabawa }: \frac{88 \times 180}{949} \approx 17 \\
& \text { Sokoto }: \frac{710 \times 180}{949} \approx 135 \\
& \text { Wurno }: \frac{88 \times 180}{949} \approx 17
\end{aligned}
$$

\section{Step 3}

Monthly clearance days were used for the recruitments (virtually all corps members turn in for clearance on these days). Every fifth successive and consenting female corps member on the clearance register was enrolled but after explaining to them the aim and objectives of the study and assuring them of confidentiality. 180 questionnaires were administered but 162 were completed and returned, bringing the response rate to $90 \%$.

\section{Evaluation}

A scoring system was adapted for the 9 questions assessing respondents' knowledge of EC. Thus, $\geq 5$ correctly answered questions are considered good, while $\leq 4$ correctly answered are considered to have poor knowledge of EC.

\section{Statistical analysis}

Data were entered into and analysed using SPSS version 20.0. Age was expressed as the mean \pm S.D of the studied group. Charts were used to present frequencies. Tables $1-5$ were used to present variables used in defining association between EC knowledge and some sociodemographic variables. Pearson Chi-Square test was used to validate the statistics at $\mathrm{P}$-value of $\leq 0.05$.

\begin{tabular}{lllllll}
\hline & \multicolumn{2}{l}{ Cases } & & & \\
& \multicolumn{2}{l}{ Valid } & & Did not know/declined to respond & Total \\
\cline { 2 - 7 } & N & Percent & N & Percent & N & Percent \\
\hline \multirow{2}{*}{ EC Knowl * Independent Variables } & 155 & $95.70 \%$ & 7 & $4.30 \%$ & 162 & $100.00 \%$ \\
\hline
\end{tabular}


Table 2 EC Knowl. *tribe crosstabulation

\begin{tabular}{|c|c|c|c|c|c|c|}
\hline & & \multicolumn{4}{|l|}{ Tribe } & \multirow{2}{*}{ Total } \\
\hline & & Hausa & Yoruba & IGBO & Others & \\
\hline \multirow{2}{*}{ EC knowl } & Good $=5$ and above scores & 4 & 17 & 5 & II & 37 \\
\hline & Poor=4 and below scores & 28 & 29 & 30 & 31 & 118 \\
\hline Total & & 32 & 46 & 35 & 42 & 155 \\
\hline
\end{tabular}

Pearson Chi-Square $=8.505, \mathrm{df}=3 \& \mathrm{P}=0.037$

Table 3 EC knowl. *religion crosstabulation

\begin{tabular}{|c|c|c|c|c|}
\hline & & \multicolumn{2}{|c|}{ Religion } & \multirow{2}{*}{ Total } \\
\hline & & Islam & Christianity & \\
\hline \multirow{2}{*}{ EC knowl } & Good $=5$ and above scores & 15 & 22 & 37 \\
\hline & Poor $=4$ and below scores & 30 & 88 & 118 \\
\hline Total & & 45 & 110 & 155 \\
\hline
\end{tabular}

Pearson Chi-Square $=3.124, \mathrm{df}=\mathrm{I} \& \mathrm{P}=0.077$

Table 4 EC knowl. *state crosstabulation

\begin{tabular}{llllllllll}
\hline & & \multicolumn{2}{c}{ State } & & & & & Total \\
\cline { 3 - 7 } & & N-W & N-E & N-C & S-W & S-S & S-E & \\
\hline \multirow{2}{*}{ EC knowl } & Good=5 and above scores & 4 & 3 & 16 & 8 & 1 & 5 & 37 \\
Total & Poor=4 and below scores & 16 & 23 & 18 & 17 & 17 & 27 & 118 & 18 \\
& & 20 & 26 & 34 & 25 & 18 & 32 & 155 \\
\hline
\end{tabular}

Pearson Chi-Square $=\mid 7.830, d f=5 \& P=0.003$

Table 5 EC knowl. *course crosstabulation

\begin{tabular}{|c|c|c|c|c|c|}
\hline & & \multicolumn{3}{|l|}{ Course } & \multirow{2}{*}{ Total } \\
\hline & & Medical and related & Other sciences & Other disciplines & \\
\hline \multirow{2}{*}{ EC knowl } & Good $=5$ and above scores & I & 13 & 23 & 37 \\
\hline & Poor $=4$ and below scores & 5 & 31 & 82 & 118 \\
\hline Total & & 6 & 44 & 105 & 155 \\
\hline
\end{tabular}

Pearson Chi-Square $=1.174, \mathrm{df}=2 \& \mathrm{P}=0.556$

\section{Ethical permission}

This was obtained from the office of the state coordinator of the NYSC, Sokoto State (Appendix 2) and the informed consent of the recruited female youth corps members with/without that of their spouses were sought.

\section{Results}

\section{Socio-demographic stratification}

162 of the 180 questionnaires served were completed and returned by the respondents. This gave a response rate of $90 \%$. The mean age of the respondents was $25.4 \pm 2.5$ years. The socio-demographic distributions of the respondents are as shown in Figures 1-6. It is obvious in fig 1a that the NYSC scheme at any state represents Nigeria in its distributions of its people by ethnicities. Similarly, it is obvious from Figure 2 that the female corps member has Christian's preponderance, in a Muslims dominated northern Sokoto state of Nigeria, which is an objective of the NYSC scheme. Figure 3 showed that most of the youth corps members are single which obviously is because of the category of Nigerians involved in the scheme. And Figure 4 showed how the respondents are spread across the 6 geopolitical zones of Nigeria. Figure 5 and Figure 6 depict the distribution of the respondents into whether they are graduates of a Polytechnic (HND) or a University or a degree awarding College of Education ( $1^{\text {st }}$ or $2^{\text {nd }}$ degrees).

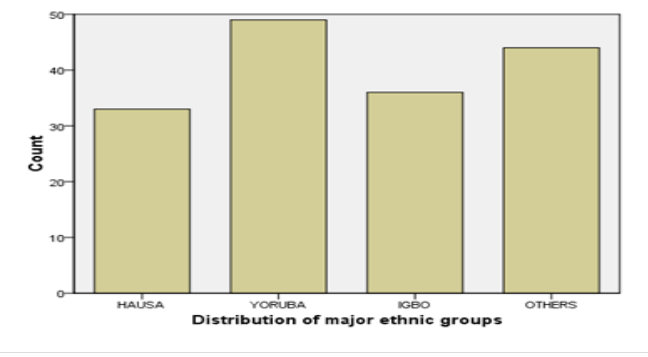

Figure I Distribution of respondents into ethnicities/tribes. 


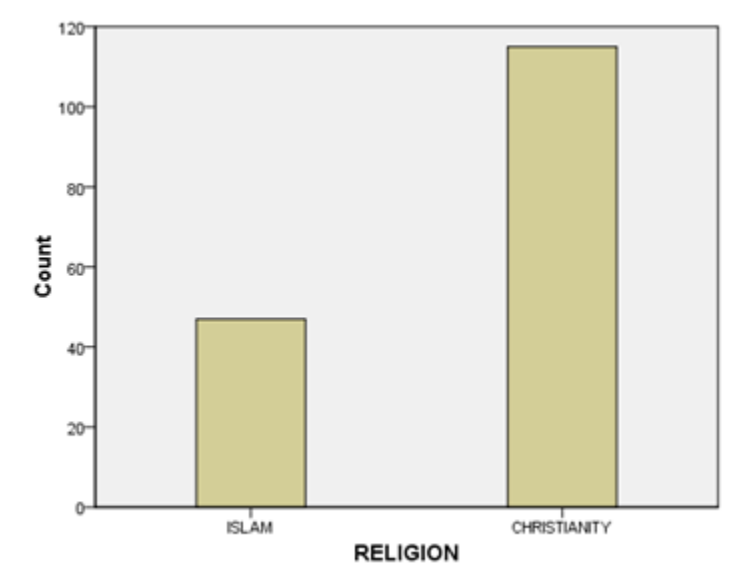

Figure 2 Distribution of respondents into their religious groups.

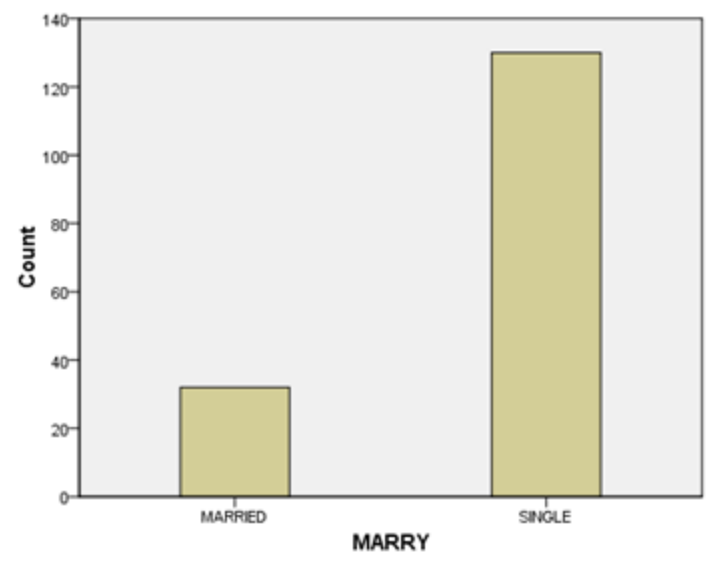

Figure 3 Distribution of respondents into married or single.

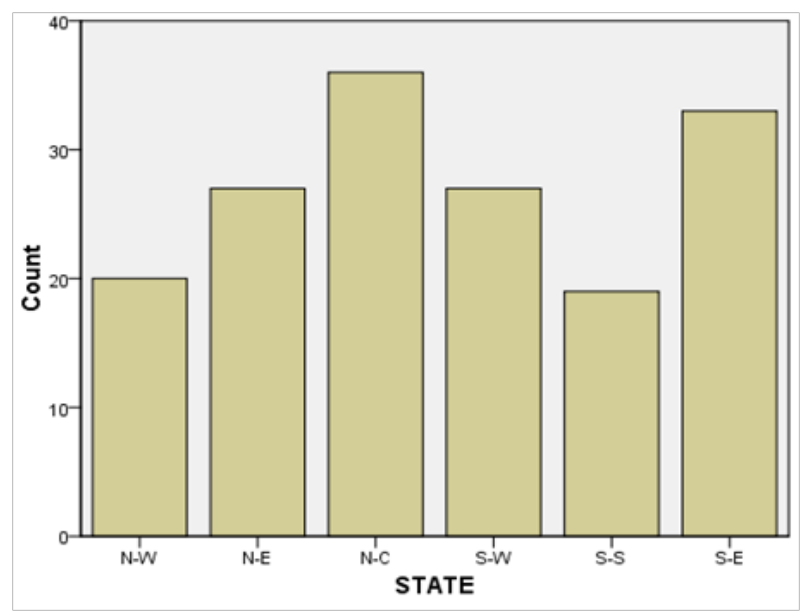

Figure 4 Distribution of respondents into states/geopolitical zones.

$\mathrm{N}-\mathrm{W}$, north-west; N-E, north-east; N-C, north-central; S-W, south-west; S-S south-south; S-E, south-east.

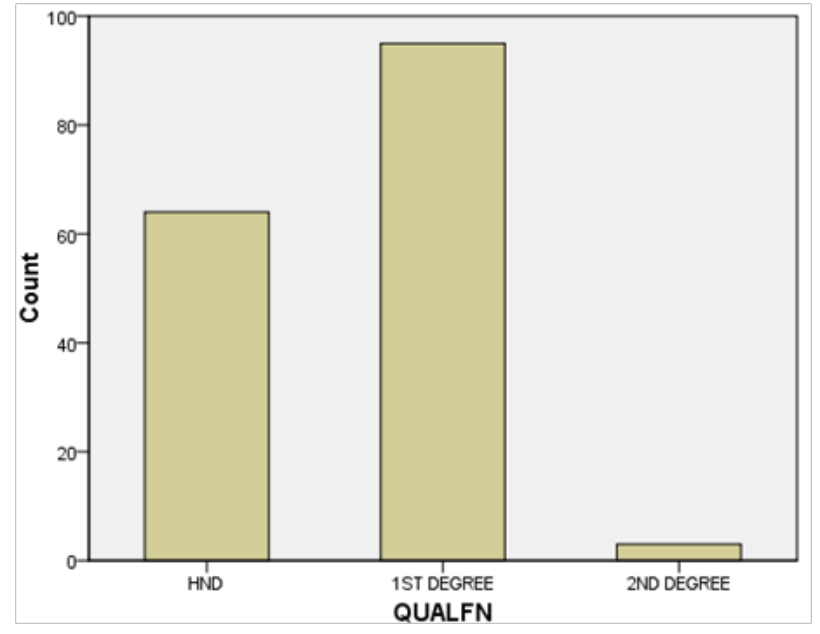

Figure 5 Distribution of respondents into the type of degrees they have.

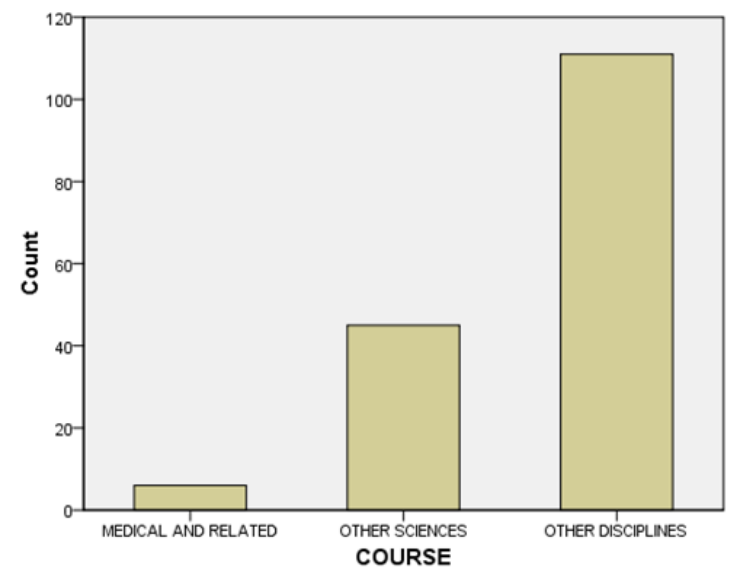

Figure 6 Distribution of respondents into discipline of first degree.

\section{Knowledge of emergency contraceptive}

$87(53 \%)$ of the respondent know what EC is, $46(28.4 \%)$ don't know, $22(13.6 \%)$ were not sure what EC is while, 7 (4.3\%) decline to answer whether or not they know EC. On the other hand, 37 (22.8\%) of the respondents showed good knowledge of EC, 118 (72.8\%) displayed poor knowledge of EC and 7 of them (4.3\%) did not respond to the question. In the same vein, only $31(35.6 \%)$ of the respondents that indicated they know EC were able to demonstrate good knowledge of EC (Figure 7). 29 of the respondents (17.9\%) know hormonal/pills types EC, much fewer, 2 (1.2\%) of them knows Copper-Intrauterine Device (Cu-IUD) and 131 (80.9\%) of them declined answering the question. Similarly, on the question of whether respondents know any oral EC, only $26(16 \%)$ answered in the affirmative, a huge number, 96 $(59.3 \%)$ answered no and another handful of them, 40 (24.7\%) did not answer the question. And about $53.8 \%(14 / 26)$ of the respondents that answered yes to oral EC were able to mention any examples (Figure 8 ) and yet a lower portion, $50 \%(13 / 26)$ of those who answered yes to the question of oral EC knew how it is used. 


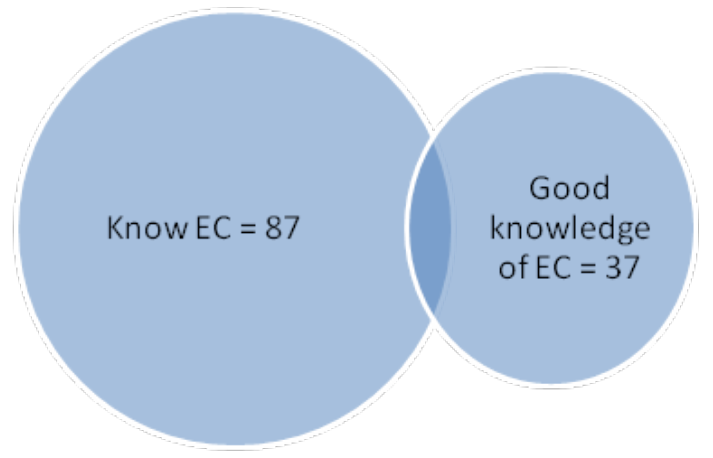

Figure 7 Respondents that know EC, those that have good knowledge of EC and those that have both.

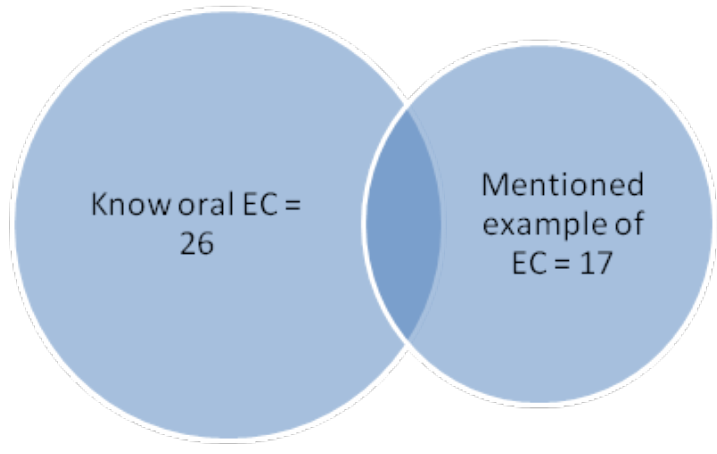

Figure 8 Respondents that indicated they know any oral EC, those able to mention the example and those that demonstrated both.

\section{Attitudes towards emergency contraceptives}

While $44.4 \%$ (72) of the respondents believed it is morally alright to utilize EC when there is need, $32.1 \%$ (52) said it is not morally okay and $23.5 \%(38)$ of the respondents chose not to answer on that field. Only 23 (14.2\%) of the respondents ever used an EC, a huge 127 (78.4\%) of them never applied it and $12(7.4 \%)$ of them did not answer the question. Furthermore, only $56.5 \%$ (13) of the 23 respondents that ever had reasons to apply EC were able to mention the type of EC they used. And 24 (14.9\%) of respondents volunteered that they had ever been involved in an act that required EC, 112 (69.1\%) of them answered no and $26(16.0 \%)$ declined answering the question.

\section{Practice of emergency contraceptives}

Out of the 24 respondents above that ever got involved in an act that required EC only 9 (37.5\%) of them access EC (Figure 9). It is obvious most of the respondents hardly access EC services, as most of them, $135(83.3 \%)$ declined answering the fields. Only $10(6.2 \%)$ access it through family planning clinic, $14(8.6 \%)$ get through a private doctor and $3(1.9 \%)$ others by other sources including chemists shops. Only $16(9.9 \%)$ of our respondents believed EC was effective for them, 27 (16.7\%) said it was not effective and $119(73.5 \%)$ refused to answer that question. Most of the respondents, $115(71.0 \%)$ have never been introduced to EC. But, $13(8.0 \%)$ were introduced by a doctor, $16(9.9 \%)$ by friends, $12(7.4 \%)$ by sexual partner and 6 $(3.7 \%)$ by other avenues including drug marketers. And just 12
(7.4\%) of them ever introduced anybody to EC, while $101(62.3 \%)$ never introduced anybody and the remaining $49(30.2 \%)$ chose not to answer this question.

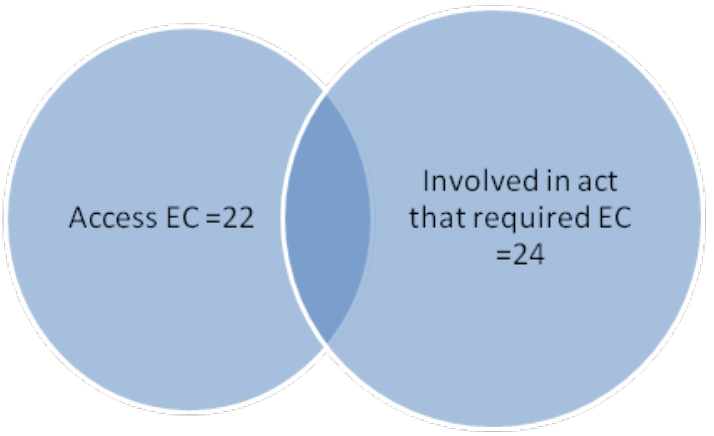

Figure 9 Respondents that ever got involved in an act that requires EC, those that access EC and those that ever got involved and accessed.

\section{Correlations of EC knowledge with some socio- demographic variables}

Out of the 162 respondents that participated in the study, 7 (4.3\%) chose not to attempt the section fielded on the knowledge of EC and it is shown in the summary presented in Table 1. Our results showed that there is a positive relationship between tribe and EC knowledge $\left(\chi^{2}=8.505, \mathrm{p}=0.037\right)$, with the Yoruba and other tribes, aside from the Hausa and Igbo likely to show better knowledge of EC. There is no strong relationship between religion and EC knowledge $\left(\chi^{2}=3.124\right.$, $\mathrm{p}=0.077$ ). Similarly, there is no good correlation between the course a respondent studied and their knowledge of $\mathrm{EC}\left(\chi^{2}=1.174, \mathrm{p}=0.556\right)$. But there was a strong positive correlation between EC knowledge and the geopolitical zone of the respondents $\left(\chi^{2}=17.830, p=0.003\right)$. With the respondents from the North-central (N-C) and South-west (S-W) states likely to have better knowledge of EC than other geopolitical zones.

\section{Discussions}

The main findings of the present study are; in a representative group of female NYSC members of Nigeria, knowledge of EC is low $(22.8 \%)$ even among those of them that signified they know it. That the concept of EC as seen in a significant number (32.1\%) of this group of Nigerian youths as having moral issues, even when there is obvious need. Records of EC use are poor and the seeking attitude even when it is necessary was equally poor. It is obvious there is little or no encouragement from any person(s) as $115(71.0 \%)$ of the respondents have never been introduced to EC to enhance its utilization. Although, a study ${ }^{17}$ reported that there was no influence of ethnicity on the utilization of EC, we have been able to demonstrate in the index study that EC knowledge is related to tribe $\left(\chi^{2}=8.505\right.$, $\mathrm{p}=0.037)$ and we showed that it was low among the respondents who are Hausa and Igbo by tribe, but the Yoruba and other tribes displayed high knowledge of EC. And this is supported by the demonstration for the first time in the present study that the respondents knowledge is influenced by their geopolitical zones of origin $\left(\chi^{2}=17.830, \mathrm{p}=0.003\right)$, that those respondents from the North-Central and South- Western states of Nigeria displayed higher knowledge of EC than their counterparts from the North-West, North-East, South-South, and South-Eastern states. 
Previous studies have examined the knowledge and use of EC among students (male and female) of higher institutions of learning. $6,11,14,16,18$ Most of the respondents in these study groups were still living off and under the guidance of their parents or some close relatives. None of the previous studies, form our search have investigated knowledge and use of EC among female graduates on mandatory national assignment away from their indigenous area, to usually a new environment without their parents close by and with a meagre stipend to cater for themselves. These, put together will increase their sexual behaviour, which may also upsurge the incidences of unwanted pregnancies and abortions that are usually handled mostly in developing countries like Nigeria by back-street abortionist. The consequences of which are usually not pleasant.

We found that about half of the respondents (53\%) are aware of EC. This is similar to what was recorded among female undergraduates $(58 \%)$, more than 10 years ago, in University of Benin SouthSouth, Nigeria. ${ }^{18}$ This is better than the $22.8 \%$ which in South Africa was reported on awareness of EC..$^{10}$ In the present study, a unified representative group showed lower EC awareness than what obtains in University of Benin. This may be explained by the relations we have earlier established to exist between EC knowledge and tribes and geopolitical zones. We have also recorded $22.8 \%$ of good knowledge of EC among our study group. This is low considering the importance of good EC knowledge in the group under consideration but it is better than the $18.5 \%$ reported among males and female students of institutions of higher learning in Osun state, South-West Nigeria. ${ }^{5}$ Similar low EC knowledge was reported in South Africa ${ }^{10}$ and same low knowledge EC was reported among women in California. ${ }^{19}$

Oral EC are more popular, readily available and more convenient to use. ${ }^{2}$ But in the present study, only $16.0 \%$ of the respondents know any oral EC and just about half of this number were able to mention any example of oral EC pills.

Less than half $(44.4 \%)$ of the respondents in the present group believe it is morally oaky to use EC when there is indication. Other respondents either chose not to answer and yet some believed it is just not okay even if there is indication. Also, just about $56.5 \%$ of the respondents who know EC ever applied it. On the other hand, a study ${ }^{10}$ in South Africa found a lower percentage (9.1\%) of those who know EC have ever used it. This present study also found that as low as $37.5 \%$ of the respondents accessed EC even after being involved in an act that obviously required it.

\section{Limitations of the study}

The relatively small sample size and considering only female NYSC members, not the general population in the study, as well as the descriptive nature of the study makes inference making difficult in the current study

\section{Conclusion}

It is obvious in the present study that the awareness, knowledge and utilization of EC among female Nigeria graduates is far below what is expected, even as the rate of EC use is expected to be higher, to avoid unplanned pregnancies. ${ }^{20}$ The rate of non-responses to questions fielded was also high and makes one to think that people don't want to volunteer information related to sexuality even though our research team have as much as possible avoided sensitive questions in the questionnaire design. To this extent, more formal sex education should be encouraged to raise awareness and knowledge. ${ }^{5,18}$ Information leaflets should also be distributed in advance to improve
EC knowledge. ${ }^{21}$ Although, a study ${ }^{22}$ in Hong Kong showed most doctors don't support EC in advance. But some others ${ }^{23,24}$ have shown abundantly that EC pills made available just as condoms will enhance the utilization. ${ }^{17,24}$ By this, the incidence of unintended pregnancies will be brought down and therefore criminal abortions and the consequences will be minimised.

\section{Acknowledgments}

We appreciate the support given to our research team by the entire staff of NYSC, Sokoto state and we are equally grateful to our female NYSC members who participated in the study.

\section{Funding}

None.

\section{Conflicts of interest}

Authors disclose no conflict of interests in publication of this study.

\section{References}

1. James Trussell. Mechanism of action of emergency contraceptive pills Contraception. 2006;74(2):87-89.

2. Gemzell-Danielsson K, Berger C, P G L L. Emergency contraception: mechanisms of action. Contraception. 2013;87(3):300-308.

3. Association of Reproductive Health Professionals. Update on emergency contraception: mechanism of action. 2011.

4. Walker DM, Torres P, Gutierrez JP, et al. Emergency contraception use is correlated with increased condom use among adolescents: Results from Mexico. J Adolesc Health. 2004;35(4):329-334.

5. Adeniji AO, AM Tijani, Owonikoko KM. Knowledge and determinants of emergency contraception use among students in tertiary institution in Osun State, Nigeria. Journal of Basic and Clinical Reproductive Sciences. 2013;2(151).

6. Daniels K, Jones J, Abma J. Use of emergency contraception among women aged 15-44: United States, 2006-2010. National Center for Health Statistics; 2013.

7. Omu AE, Oronsaye AU, Faal MK, et al. Adolescent induced abortion in Benin City, Nigeria. Int J Gynaecol Obstet. 1981;19(6):495-499.

8. Ladipo OA. Preventing and managing complications of induced abortion in Third World countries. Int J Gynecol Obstet. 1989;3:21-28.

9. Grimes DA, Benson J, Singh S, et al. Unsafe abortion: the preventable pandemic. Lancet. 2006;368(9550):1908-1919.

10. Smit J, McFadyen L, Beksinska M, et al. Emergency contraception in South Africa: knowledge, attitudes, and use among public sector primary healthcare clients. Contraception. 2001;64(6):333-337.

11. Ebuehi OM, Ekanem EE, Ebuehi OA. Knowledge and practice of emergency contraception among female undergraduates in the University of Lagos, Nigeria. East Afr Med J. 2006;83(3):90-95.

12. Morgan G, Keesbury J, Speizer I. Emergency contraceptive knowledge and use among urban women in Nigeria and Kenya. Stud Fam Plann. 2014;45(1):59-72.

13. Dittus PJ, Jaccard J. Adolescents' perception of maternal disapproval of sex: relationship to sexual outcome. J adolescent health. 2000;26(4):268278.

14. Odeyemi K, Onajole A, Ogunowo B. Sexual behavior and the influencing factors among out of school female adolescents in Mushin market, Lagos, Nigeria. Int J Adolesc Med Health. 2009;21(1):101-109. 
15. History of National Youth Service Corps (NYSC) Scheme in Nigeria. 2013.

16. Ojule JD, Oriji VK, Georgewill KN. Awareness and Practice of Emergency Contraception among Students of University of Port Harcourt, South-South Nigeria. The Nigerian Health Journal. 2008;8(12).

17. Walsh TL, Frezieres RG. Patterns of emergency contraception use by age and ethnicity from a randomized trial comparing advance provision and information only. Contraception. 2006;74(2):110-117.

18. Aziken ME, Okonta PI, Ande AB. Knowledge and perception of emergency contraception among female Nigerian undergraduates. Int Fam Plan Perspect. 2003;29(2):84-87.

19. Baldwin SB, Solorio R, Washington DL, et al. Who is using emergency contraception? awareness and use of emergency contraception among California women and teens. Womens Health Issues. 2008;18(5):360368.
20. Virjo I, Kirkkola AL, Isokoski M, et al. Use and knowledge of hormonal emergency contraception. Adv Contracept. 1999;15(2):85-94.

21. Smith LF, Whitfield MJ. Women's knowledge of taking oral contraceptive pills correctly and of emergency contraception: effect of providing information leaflets in general practice. 2. Br J Gen Pract. 1995;45(397):409-414.

22. Lo SS, Kok WM, Fan SY. Emergency contraception: knowledge, attitude and prescription practice among doctors in different specialties in Hong Kong. J Obstet Gynaecol Res. 2008;35(4):767-774.

23. Gold MA, Wolford JE, Smith KA, et al. The effects of advance provision of emergency contraception on adolescent women's sexual and contraceptive behaviors. J Pediatr Adolesc Gynecol. 2004;17(2):87-96.

24. Jackson RA, Schwarz EB, Freedman L, et al. Advance Supply of Emergency Contraception: Effect on Use and Usual Contraception-A Randomized Trial. Obstet Gynecol. 2003;102(1):8-16. 